\title{
REVIEW
}

\section{Growth hormone, IGF-I and cancer. Less intervention to avoid cancer? More intervention to prevent cancer?}

\author{
J M P Holly ${ }^{1}$, D J Gunnell ${ }^{2}$ and G Davey Smith ${ }^{2}$ \\ ${ }^{1}$ Division of Surgery, Bristol Royal Infirmary, Bristol, UK \\ ${ }^{2}$ Department of Social Medicine, University of Bristol, Bristol, UK \\ (Requests for offprints should be addressed to JMP Holly, Division of Surgery, Level 7, Bristol Royal Infirmary, Marlborough Street, Bristol BS2 8HW, UK)
}

\begin{abstract}
The GH/IGF-I axis has a clearly established role in somatic growth regulation and there is much evidence suggesting that it can play a contributing role in neoplastic tissue growth; a number of recent epidemiological reports indicate that it may also be an important determinant of cancer incidence. Whilst there have been previous reports of changes to the axis in patients with established cancers, these new studies are distinct in being prospective and the inferences that can be made from this are outlined in this review. The recent studies are considered within the context of other indirect epidemiological evidence, and together indicate that the GH/IGF-I axis may establish the level of predisposition to a number of common cancers and
\end{abstract}

indeed that such risk may be programmed from early life. There is considerable evidence for a number of possible mechanisms, both direct and indirect, which could account for the associations between GH/IGF-I levels and cancer incidence; these mechanisms are briefly summarised. The implications of the new findings are then discussed in relation to the increasing clinical usage of chronic GH administration and the need for further studies to establish any consequent increase in cancer risk. Finally the opportunities for further work to optimise cancer risk assessment and risk reduction strategies are highlighted.

Journal of Endocrinology (1999) 162, 321-330

\section{Introduction}

Since the isolation of growth hormone (GH) half-way through this century it has become increasingly clear that the GH/insulin-like growth factor-I (IGF-I) axis plays a fundamental and obligatory role in regulating normal somatic growth throughout fetal and childhood development. Over the past two decades considerable evidence has accumulated indicating that these growth factors may also play an important role in maintaining and supporting the progression of neoplastic growth. During this period there have been sporadic suggestions that GH/IGF-I may be important for the development of cancers, although the evidence for this has until recently been circumstantial. New epidemiological studies provide the first real evidence that GH/IGF-I may be important determinants of the incidence of major human cancers. These studies raise important questions in relation to both the aetiology of these cancers and the risks associated with current and future therapeutic interventions involving long-term clinical application of GH or IGF-I. They may also lay the foundations for new strategies to assess cancer risk and raise the possibility of new interventions to reduce cancer incidence. The purpose of this commentary is to review the recent epidemiological evidence in the light of our current understanding of the pathophysiology of cancer and to discuss its implications, particularly in relation to existing and future interventions.

\section{New Epidemiology}

\section{Direct epidemiological evidence}

That circulating IGF-I may be an important determinant of the incidence of cancers is implicated by two recent studies demonstrating strong associations between circulating IGF-I levels and risk of breast cancer in premenopausal women (Hankinson et al. 1998) and prostate cancer in men (Chan et al. 1998). The strength of these studies derives from their prospective nature. There have been many reports that the GH/IGF-I axis is perturbed both locally and systemically in patients with existing cancers. Two recent reports appear to confirm the association between raised circulating IGF-I levels and increased risk 
Table 1 IGF-I as a risk factor for cancers of the prostate and breast

\begin{tabular}{|c|c|c|c|}
\hline & $\begin{array}{l}\text { Relative } \\
\text { risk }\end{array}$ & Comparison & Reference \\
\hline \multicolumn{4}{|l|}{ Prostate } \\
\hline IGF-I & $2 \cdot 4$ & & \\
\hline IGF-I and IGFBP-3 (aged >60 years) & $7 \cdot 9$ & Upper vs lower quartile & Chan et al. (1998) \\
\hline Testosterone and SHBG & $2 \cdot 6$ & Upper vs lower quartile & Gann et al. (1996) \\
\hline PSA & $5 \cdot 5$ & $2 \cdot 0-3 \cdot 0 \mathrm{ng} / \mathrm{ml}$ vs $<1 \cdot 0 \mathrm{ng} / \mathrm{ml}$ & Gann et al. (1995) \\
\hline IGF-I (premenopausal, aged $<50$ years) & $4 \cdot 6$ & \multirow[t]{2}{*}{ Upper vs lower tertile } & \multirow[t]{2}{*}{ Hankinson et al. (1998) } \\
\hline IGF-I and IGFBP-3 (premenopausal, aged <50 years) & $7 \cdot 3$ & & \\
\hline Oestradiol and SHBG (postmenopausal) & $5 \cdot 2$ & \multirow{2}{*}{ Upper vs lower quartile } & \multirow{2}{*}{ Dorgan et al. (1997) } \\
\hline Testosterone (postmenopausal) & $6 \cdot 2$ & & \\
\hline HRT, contraceptive use & $1 \cdot 0-2 \cdot 0$ & - & \multirow{2}{*}{ Harris et al. (1996) } \\
\hline Early menarche, late menopause, nulliparity, age at first birth & $1 \cdot 5-3 \cdot 0$ & - & \\
\hline
\end{tabular}

of prostate and breast cancers, but both relate to patients with either newly diagnosed or in situ disease (Bohlke et al. 1998, Wolk et al. 1998). There are, however, important distinctions between the prospective studies and those of subjects with existing cancers. It is evident that cancer can elicit a number of changes to the circulating IGF system; increases in proteolysis of insulin-like growth factorbinding protein-3 (IGFBP-3) and concentrations of IGFBP-2 have been documented in many different cancers. Such changes in binding proteins would alter the distribution and clearance of IGFs, affecting circulating concentrations even if production were unaltered. As disease progresses, general derangement of metabolism will have further profound effects on the IGF system. Any predisposing disturbance within the IGF system is therefore very likely to be masked once the disease has become established due to the compounding effects of tumourderived components and the alterations induced as part of the host response to the cancer. The recent prospective reports are the first large studies showing that circulating IGF-I, measured before disease presentation, is strongly associated with risk of subsequent breast and prostate cancers. Such prospective data have entirely different implications, particularly as the data relate to IGF-I concentrations within the normal range. Another recent study, based on an 18 year follow-up of French policemen, reports that circulating $\mathrm{GH}$ concentrations $(2 \mathrm{~h}$ after an oral glucose tolerance test) are significantly associated with increased risk of malignancy (Maison et al. 1998); again this was a prospective study in which $\mathrm{GH}$ measurements were undertaken in a healthy male population and related to subsequent cancers detected in a long-term follow-up (mean 18 years).

The identification of IGF-I as a risk factor for cancers came from nested case-controlled studies undertaken within the Physicians and Nurses Health Studies performed in the USA. The former covered nearly
15000 men aged 40-82 years with 152 confirmed cases of prostate cancer in whom plasma IGF-I measurements had been made, on average 7 years prior to diagnosis of the cancer; the latter covered 121700 women aged 30-55 years with 397 confirmed breast cancers (76 premenopausal) in subjects in whom plasma IGF-I had been measured in samples taken on average 28 months prior to diagnosis. The relative risk ( $R R$ ) of prostate cancer associated with a circulating concentration of IGF-I in the upper quartile of the normal range was $2 \cdot 4$ when compared with the lower quartile (Table 1), but when IGFBP-3 concentrations were also included in a multivariate analysis the RR increased to $4 \cdot 3$; the $\mathrm{RR}$ was even higher, $7 \cdot 9$, in men over the age of 60 years (Chan et al. 1998). The association remained when cases diagnosed within 5 years of blood sampling were excluded to remove the potential influence of preclinical undiagnosed cancers, which could themselves influence IGF-I levels. The increased risk of breast cancer associated with circulating IGF-I concentrations in the upper tertile of the normal range was only apparent for cases of premenopausal breast cancer, with an RR of $2 \cdot 3$; this increased to 4.6 in premenopausal women less than 50 years of age and again controlling for IGFBP-3 concentrations increased the RR further to $7 \cdot 3$ (Hankinson et al. 1998).

Cancers of the breast and prostate have generally been considered to be sex hormone dependent. For prostate cancer, the strongest link reported with androgen status has been a positive association with testosterone concentrations when these were controlled for levels of sex hormone-binding globulin (SHBG); a testosterone level in the upper quartile gave an RR of $2 \cdot 6$ (Gann et al. 1996) (Table 1). For breast cancer the strongest associations have been reported in postmenopausal women, with an RR of $5 \cdot 2$ for non-SHBG bound oestradiol in the upper quartile of normal and an RR of 6.2 for testosterone in the upper quartile (Dorgan et al. 1997) (Table 1). The RRs 
associated with marked perturbations in sex steroid status, for example with contraceptive use or hormone replacement therapy (HRT) have been much lower, generally between $1 \cdot 0$ and $2 \cdot 0$. Risks associated with indices of duration of exposure such as early menarche, late menopause, nulliparity or late age at first birth are of a similar order, RR 1.5-3.0. Whilst the calculated RR of prostate cancer associated with a serum prostatespecific antigen (PSA) level between 2.0 and $3.0 \mathrm{ng} / \mathrm{ml}$ (compared with $<1 \cdot 0 \mathrm{ng} / \mathrm{ml}$ ) was high, $5 \cdot 5$, this was thought to be overestimated due to the presence of subjects with undiagnosed cancers (Gann et al. 1995) (Table 1). Obviously, as these risks are based upon different subdivisions of various cohorts they are not directly comparable; however, it is clear that the associations recently described between circulating IGF-I and cancer incidence are at least as strong as those with previously described risk factors.

The recent studies providing direct evidence linking GH/IGF-I with cancer incidence need confirmation by other large prospective cohorts with long-term follow-ups and sufficient years between sampling and disease diagnosis. The duration of disease before clinical presentation may be long, many years for some prostate cancers; observations made shortly before clinical diagnosis may therefore just reflect preclinical disease. Such long-term studies are limited in number by the relatively recent introduction of reliable assays for GH and IGF-I. The prospective study of $\mathrm{GH}$ in the French police cohort with an 18 year follow-up was based on results from an early GH assay, the imprecision of which may have resulted in an underestimate of the association with malignancy (Maison et al. 1998). However, whilst these studies are still few in number, many other recent epidemiological reports describe associations that would be consistent with a strong effect of GH/IGF-I on cancer incidence.

\section{Indirect epidemiological evidence}

The GH/IGF-I axis has a central role in regulating somatic longitudinal growth and weak but consistent associations between final adult height and incidence of both breast (Hunter \& Willett 1993) and prostate (Giovannucci et al. 1997) cancers have been reported. Similar associations have also been reported for colorectal (Albanes et al. 1988, Chute et al. 1991) and haematopoietic cancers (Leon et al. 1995). Metabolic and hormonal influences on somatic growth in childhood are predominantly on the long-bone epiphyseal growth-plates, as reflected by leg length measurements. Such measurements in children less than 8 years old are significantly related to incidence of cancer later in life in both sexes, particularly hormonally related cancers (Gunnell et al. 1998a,b). The IGFs are important for intrauterine, in addition to postnatal growth, and many studies have found positive associations between circulating IGF-I and birthweight. Positive associations between birthweight and the incidence of cancers of both the breast (Michels et al. 1996) and prostate (Tibblin et al. 1995) have also been described, providing further indirect evidence of a possible role for growth factors. Height and birthweight only provide indirect evidence of nutrition and endocrine status throughout early life. Few studies have assessed the influence of such early life exposures on adult cancer risk by direct measurements in childhood. High calorie intake in childhood has been associated with a significant increase in risk of non-smoking-related malignancies later in life (Frankel et al. 1998). Nutritional intake is a strong determinant of hepatic IGF-I production and hence circulating IGF-I concentrations (Thissen et al. 1994). These studies imply that the risk of cancer may in part be established from very early life. Nutrition in early life may have a 'programming' effect, via IGF-I, determining not only longitudinal growth but also cancer risk later in life.

In addition to associations with physiological variations in IGF-I, there is evidence that pathological variations in IGF-I may also affect cancer incidence. Subjects with acromegaly can have elevated circulating IGF-I concentrations for many years; however, few studies have included sufficient cases to assess whether this condition is associated with increased incidence of other cancers. An increased number of deaths from breast cancer was reported in a personal series of 256 cases seen over a 20 year period (Nabarro 1987). A significant increase in deaths from malignancies, particularly prostate and colorectal, was also reported in a follow-up of 166 cases seen over a 30 year period in Sweden (Bengtsson et al. 1988). A more recent cohort study was initially reported in abstract form (Orme et al. 1996). The results reported on 1379 patients with acromegaly, from 15 centres around the UK, and indicated a significant increase in incidence of cancers (123 cases, standardised incidence ratio (SIR) 1.27; $P=0.006)$ and cancer mortality (98 deaths, standardised mortality ratio (SMR) $1.56 ; P<0 \cdot 001)$ particularly due to colonic carcinoma (SMR 3.03; $P<0.001$ ) and breast cancer (SMR 1.92; $P=0 \cdot 018$ ). In the full paper, subsequently reporting the final analysis of this study (Orme et al. 1998), the results had altered somewhat, being based on 1362 patients with an overall cancer incidence of 79 cases (SIR 0.76; 95\% confidence interval (CI) $0 \cdot 60-0 \cdot 95$, one-sided $P=1 \cdot 00$ ) now being lower than expected. Overall cancer mortality was no longer significantly raised (83 cases, SMR 1.16; $95 \%$ CI $0 \cdot 92-1 \cdot 44, P=0 \cdot 10$ (one-sided)), although deaths from colonic cancers were still significantly increased (SMR $2 \cdot 47 ; 95 \%$ CI 1.31-4.22, $P=0 \cdot 003$ ), but those from breast cancer did not reach conventionally accepted levels of statistical significance (SMR 1.60; 95\% CI 0.85-2.74, $P=0 \cdot 07)$.

In a number of studies recent childbirth has been associated with a transient increase in risk of breast cancer 
(Lambe et al. 1994); pregnancy is associated with major changes in the GH/IGF system. Pituitary GH secretion is suppressed and replaced in the circulation by a variant form of $\mathrm{GH}$ produced by the placenta. The episodic profile of pituitary GH secretion is replaced by a profile of placenta-derived GH resembling that seen in patients with acromegaly (Eriksson et al. 1989). There is a moderate rise in circulating IGF-I concentration through pregnancy, but much less than generally seen in acromegaly. However, this is probably due to increased clearance resulting from the dramatic increase in proteolysis of the main circulating carrier protein IGFBP-3 (Davenport et al. 1990). As a consequence the tissue availability of circulating IGF-I is increased much more than is reflected by the total concentration. Such an increase in IGF-I throughout the months of pregnancy may underlie the transient increase in risk of breast cancer. Conversely, the risk of prostate cancer is significantly reduced in subjects with diabetes (Giovannucci et al. 1998), a condition characterised by GH resistance and reduced IGF-I levels/ activity.

In addition to changes in the risk of cancer due to pathophysiological variations in IGF-I, it is possible that dietary and pharmacologically induced changes in IGF-I levels may also affect such risk. A recent epidemiological study of circulating IGF-I concentrations in a large adult population identified only age, sex and alcohol consumption as significantly affecting serum IGF-I levels, with IGF-I being positively associated with alcohol consumption (Goodman-Gruen \& Barrett-Connor 1997). Several studies have identified a linear association between risk of breast cancer and increasing alcohol consumption (SmithWarner et al. 1998) and a significant risk of breast cancer associated with HRT has been reported to occur only in women with regular alcohol intake greater than $5 \mathrm{~g} /$ day (Zumoff 1997). An effect of alcohol on oestrogen levels has been suggested to explain these associations (Hankinson et al. 1995); an effect of alcohol on circulating IGF-I could provide an alternative explanation.

Tamoxifen has a number of effects on the IGF system in women with breast cancer, decreasing circulating IGF-I concentrations and reducing proteolysis of IGFBP-3 (Helle et al. 1996). These changes would be consistent with a shift in the balance between IGF-I and intact (high-affinity) IGFBP-3. Preliminary data released from a prophylactic intervention trial of tamoxifen in the USA indicated around a $45 \%$ reduction in breast cancer incidence (Breast Cancer Prevention Trial (BCPT), NSABP, details available on Website (http://www.cancertrials.nci. nih.gov)); changes induced in the IGF system could contribute to this dramatic effect.

All the evidence from the epidemiology appears to implicate an association predominantly with just the hormonally responsive epithelial cancers (mainly breast, prostate and colorectal cancers); this may indicate a common underlying causal link.

\section{Potential Mechanisms Linking GH/IGF-I and Cancer Incidence}

\section{Indirect mechanisms}

There are a number of potential mechanisms that could explain the strong associations between circulating IGF-I levels and cancer incidence (Fig. 1): levels of IGF-I could merely be reflecting overall sex steroid activity; alternatively IGF-I could be affecting steroid levels and/or amplifying sex steroid actions in the breast and prostate; or IGF-I levels could be having a direct effect on the development of cancer in these tissues.

The simplest explanation could be that IGF-I levels are just a reflection of overall integrated sex steroid activity. Sex steroids can modulate the GH/IGF-I axis at many levels. Steroids can directly affect pituitary GH secretion; they can affect IGF-I levels by altering production directly or by altering levels of IGF-binding proteins and hence affecting clearance (Clark \& Rogol 1996). The associations could therefore arise because serum IGF-I is a surrogate of overall steroid activity which in turn is related to cancer risk. As ovarian steroid levels are higher in premenopausal women, a more dominant role of such steroids in determining IGF-I levels may explain why an association with breast cancer was observed in these but not in postmenopausal women. In contrast, the risk of breast cancer associated with gonadal steroid levels appears stronger in postmenopausal women; this, however, probably just reflects the measurements being a more accurate reflection of the more stable circulating steroid levels that occur after the menopause. In premenopausal women the cyclical variations in circulating steroid concentrations makes assessment of overall exposure in the breast very difficult. Possibly levels of a steroid-responsive factor such as IGF-I better reflect such integrated exposure than any direct measure of gonadal steroids themselves. The very similar association between IGF-I levels and prostate cancer is, however, difficult to reconcile with the argument that IGF-I levels are just a reflection of steroid activity, since androgen effects on the GH/IGF-I axis differ from those of oestrogens (Clark \& Rogol 1996). The association between prostate cancer risk and IGF-I was stronger in the men over 60 years of age, when androgens might be expected to have less influence (Chan et al. 1998). The strength of the associations between IGF-I and breast and prostate cancers also suggest that they are unlikely to be due to IGF-I merely acting as a surrogate of steroid status. These interactions could be untangled by multivariate analysis if all the appropriate measurements were available in a sufficiently large cohort.

An alternative explanation might be that IGF-I determines steroid levels or actions. IGF-I is a powerful amplifier of gonadotrophin action, enhancing the production of gonadal steroids from both the ovary (Giudice 1992) and the testis (De Mellow et al. 1987). The 


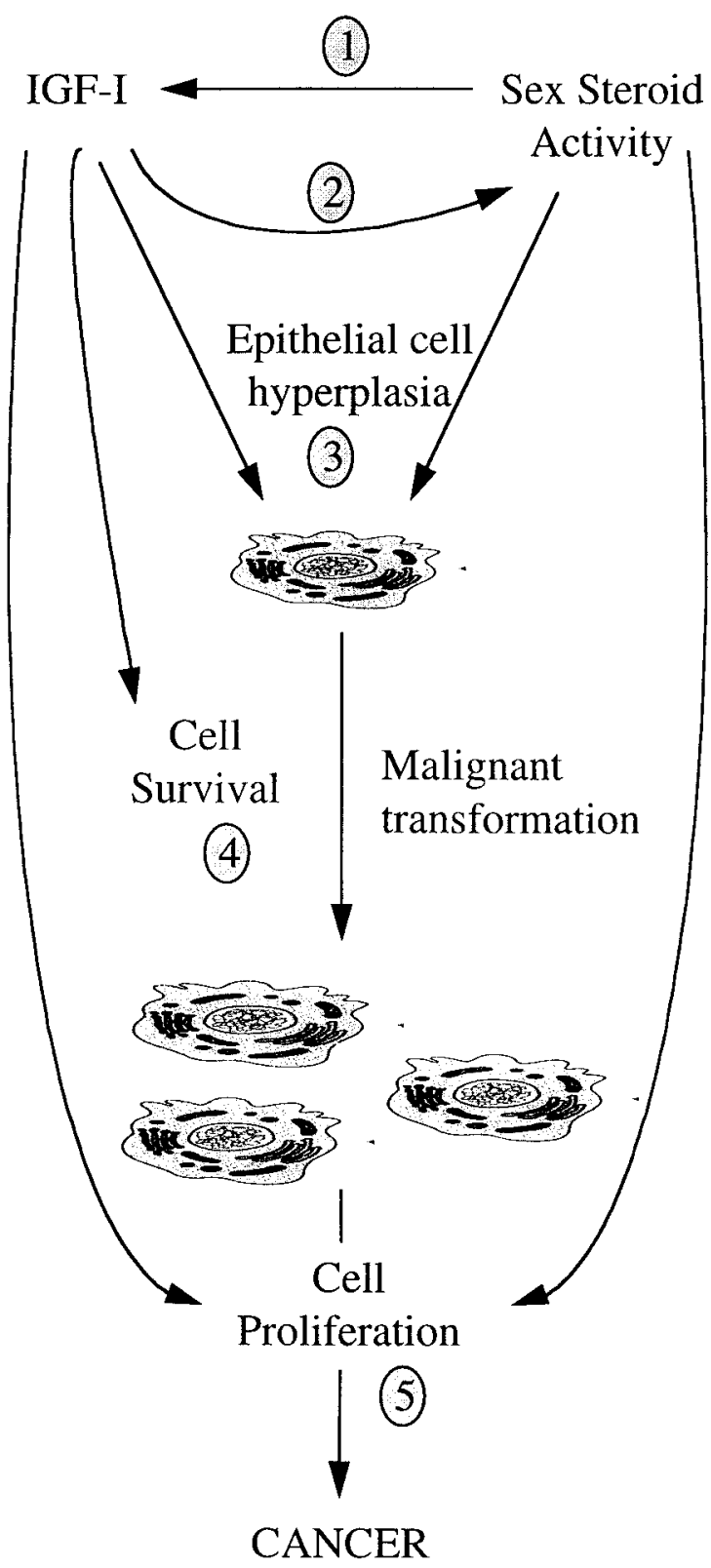

Figure 1 Potential mechanisms linking IGF-I and cancer. (1) Circulating IGF-I levels reflect, and therefore are a surrogate for, overall sex steroid activity. (2) IGF-I levels determine sex steroid activity. (3) IGF-I, directly or via sex steroids, increases epithelial cell proliferation - increasing predisposition to neoplastic transformation. (4) IGF-I promotes inappropriate survival of 'damaged' cells initiating neoplasia. (5) IGF-I enhances growth of neoplasia.

proliferative effects of steroids in breast and prostate can also be potentiated by IGF-I (Westley \& May 1994, Marcelli et al. 1995), indeed IGF-I has been reported to be able to activate the androgen receptor in the absence of androgens in prostate cells (Culig et al. 1994) and the oestrogen receptor in the absence of oestrogens in breast cells (Lee at al. 1997). Increased IGF-I, derived from the circulation, could therefore enhance and add to the effects of steroids on the breast and prostate. Hyperplasia of the breast following GH or IGF-I administration to primates ( $\mathrm{Ng}$ et al. 1997), hyperplasia of the prostate in young men with acromegaly (Colao et al. 1998), and increased epithelial cell proliferation in the colon of subjects with acromegaly which correlated with circulating IGF-I levels (Cats et al. 1996) have all been described. Greater cell turnover in these tissues could increase disposition to neoplastic transformation (Cohen \& Ellwein 1990). Acromegaly is generally accompanied by organomegaly and this may contribute to the reported increases in cancer incidence associated with this condition. A combination of such potential interacting mechanisms involving steroid effects on IGF-I and IGF-I effects on steroids is plausible to explain the associations with breast and prostate cancers.

\section{Direct mechanisms}

If the association between circulating IGF-I and cancer incidence reflects a direct causal link, then the simplest explanation would be that the mitogenic action of IGF-I increases cell turnover in the tissues, which in turn increases disposition to neoplastic transformation (Cohen \& Ellwein 1990). However, the degree to which variations in IGF-I concentration in the circulation within the normal range would affect cell turnover in different tissues is unknown. A direct effect of IGF-I on cancer incidence is, however, supported by a more powerful argument that has arisen from work demonstrating that IGF-I is critical for maintaining cell survival, particularly of transformed cells (Baserga et al. 1997, Resnicoff \& Baserga 1998).

Most human tumours develop by a multistep process in which cells acquire growth advantage by genetic damage involving an accumulation of mutations. Spontaneous gene mutations undoubtedly occur frequently and naturally throughout life and such events may be increased by exogenous mutagens (Loeb 1991). The body, however, has sophisticated defence mechanisms to delete such damaged cells. Genetic damage is detected by internal checks, which then direct the cell to commit suicide in an ordered manner through the process called apoptosis. Such internal signals for apoptosis can be overridden by external 'survival' signals. The most potent survival factor for many cell types appears to be IGF-I (Barres et al. 1992, Harrington et al. 1994) and as IGF-I is significantly more abundant than other growth factors and cytokines it is probably the predominant physiological survival factor in most tissues. The concentration of IGF-I present throughout most tissues is in excess of that required for maximal cell receptor stimulation, the high concentrations being maintained by the specific binding proteins which delay IGF-I clearance. The binding proteins have higher affinities for IGF-I than the cell receptors. The main carrier 
protein, IGFBP-3, is therefore a key determinant of IGF-I availability and actions. Recent evidence indicates that it may have added importance because it also has intrinsic IGF-independent actions promoting apoptosis of prostate (Rajah et al. 1997) and breast epithelial cells (Gill et al. 1997). Complexes of IGF-I and IGFBP-3 are abundant throughout the body and the balance between their survival and death signals may establish a 'defence' threshold that determines the extent that damaged cells may survive to accumulate mutations and develop into a tumour.

Initial mutations can result in fragility of the DNA within damaged cells that inappropriately survive; these may then accrue further mutations to progress into a tumour (Loeb 1991, Orr-Weaver \& Weinberg 1998). Both GH and IGF-I have been reported to increase chromosome fragility both in vitro (Tedeschi et al. 1993) and in vivo (Cianfarani et al. 1998).

That an increase in the concentration of IGFs can predispose to tumour development is supported by much experimental evidence in addition to the clinical evidence of acromegaly described above. Transgenic mice that overexpress GH are susceptible to an increased frequency of mammary tumours (Tornell et al. 1992). Increased malignancies, including that of the breast, have also been reported in IGF-II transgenic mice (Rogler et al. 1994, Bates et al. 1995). Overexpression of IGFBP-4 in malignant prostate epithelial cells resulted in increased apoptosis during culture and reduced the incidence of tumours and delayed their development when these cells were injected into nude mice (Damon et al. 1998). Other experiments, involving transgenic expression of oncogenic viruses in mice, have also identified focal induction of endogenous IGF-II expression as being involved in the resultant tumour development (Cariani et al. 1991, Schirmacher et al. 1993, Christofori et al. 1994). Such focal induction of IGF-II expression has been reported not to affect the proliferation of premalignant cells but to reduce the incidence of apoptosis fivefold (Christofori et al. 1994). This would be consistent with apoptosis providing a defence against malignant transformation which could be overcome by a survival signal provided by IGF-receptor activation.

Apoptosis, like all cellular functions, is a highly regulated process, modulated by many internal and external cell signals. External signals include cytokines and chemotherapeutic agents that promote apoptosis and hormones and growth factors which reduce apoptosis. If all mutations were detected and resulted in initiation of apoptosis then tumours would not develop. The potent survival effects of IGF-I may be counterbalanced by IGFBP-3, thus the balance between their levels may establish a threshold for cell apoptosis. More IGF-I with less IGFBP-3 could increase this threshold and hence increase the likelihood that mutated cells survive and progress to form tumours. It is now recognised that manipulation of this threshold by agents that promote apoptosis is a valuable strategy for restricting tumour growth (Fisher 1994). The level at which such a threshold is set by the hormonal environment may determine the body's defences against tumour development and this may be as, if not more, critical than the initial mutations for the incidence of cancers. The new studies linking IGF-I and cancer incidence and other recent reports showing that oestrogen modifiers can dramatically reduce cancer incidence (Lancet, 2 May 1998, $\mathrm{p}$ 1335), together with the experimental evidence are all consistent with the hormonal milieu determining such a disposition to developing tumours.

\section{Administration of GH: Less Intervention to Avoid Cancer?}

The availability of recombinant $\mathrm{GH}$ initiated widespread investigations of its utility for therapeutic intervention. Clinical administration of $\mathrm{GH}$ was initially restricted to young subjects with GH deficiency (GHD), to improve longitudinal growth. This was subsequently extended to include girls with Turner's syndrome (Taback et al. 1996). The market for GH grew considerably following many studies indicating that $\mathrm{GH}$ could also benefit some adult subjects with GHD (Carroll et al. 1998). This led some to enthusiastically advocate therapy being extended from a few childhood years to throughout adult life; others have been more circumspect over its benefits and potential problems (Besser 1997). A number of studies have shown that around 50\% of adults with GHD may have normal circulating IGF-I levels and, even following low GH doses, many treated subjects have IGF-I levels raised to high normal levels or above (Cuneo et al. 1998). Recent consensus guidelines recommend titration of dosage for individual subjects, with serum IGF-I measurements advanced as the best marker of GH action (Invited Report of a Workshop 1998). If many untreated subjects start with serum IGF-I levels within the normal range, then clearly GH administration may increase the IGF-I levels at least towards the high end of normal. Other studies have indicated that administration of $\mathrm{GH}$ at doses sufficient to normalise serum IGF-I may not be sufficient to normalise intermediate metabolism (Lucidi et al. 1998). This has been attributed to the broad peak of serum GH levels following subcutaneous injection being more potent than endogenous pulsatile $\mathrm{GH}$ at stimulating IGF-I, but less potent with respect to metabolic effects (Jörgensen et al. 1990). The extent to which serum IGF-I should be increased and whether such increases incur additional risk of breast, prostate, colorectal or other cancers, are obvious concerns in light of the new epidemiological data. In addition to replacement therapy, administration of GH for other indications has also been advocated, primarily for its anabolic effects either systemically, for catabolic conditions (Haymond \& Mauras 1996), or for local effects, as 
suggested for situations such as chronic heart failure (Fazio et al. 1996).

In addition to current licensed applications, there has also been much discussion of other more general applications. Considerable attention has focused on the administration of GH to counter the natural GH decline with advancing age (Corpas et al. 1993); the suggested advantages have been widely presented in articles in the UK press (e.g. The Times, 12 March 1998, Daily Mail, 21 April 1998) and GH can be acquired readily for such unlicensed applications via many sites on the Internet. The lack of regulation of Websites means many such sites offer GH for sale either directly or provide information regarding countries where such products can apparently be purchased 'over-the-counter'. These are advertised with irresponsible claims regarding use and potential benefits and with little or no caution regarding adverse effects. Such Websites abound with statements such as "human growth hormone has been widely accepted as the anti-ageing serum rejuvenating every cell in the body'; 'you can feel young again, slow down the ageing process'; 'proven scientific information on $\mathrm{GH}$ - increases activities of all other hormones' and 'our GH has been shown to raise IGF-I levels by as much as $800 \%$ '. The market for such products includes not just the elderly, but also athletes and body builders, in some areas abuse of both GH and IGF-I by such groups is apparently prevalent. From the association found in the Physicians Health Study it was calculated that every $100 \mathrm{ng} / \mathrm{ml}$ increase in circulating IGF-I concentration may correspond to an approximate doubling of the risk of prostate cancer (Chan et al. 1998); the pharmacological manipulations undertaken in athletes and to counter ageing can produce increases in IGF-I of $500-800 \mathrm{ng} / \mathrm{ml}$. Considerations of such associated risks might decrease the popularity of such abuse.

In the past some endocrinologists have argued that raising $\mathrm{GH}$ levels is safe because acromegaly is associated with no increased risk of other cancers; however, as stated previously, recent evidence from large cohorts appears to contradict this view. The recent epidemiological reports regarding breast and prostate cancers indicated that the association between cancer risk and IGF-I levels was increased if these were adjusted for levels of its main carrier protein (IGFBP-3). High IGF-I and low IGFBP-3 levels were associated with the greatest risk, suggesting that IGFBP-3 may have a protective effect. The increases in endogenous and exogenous $\mathrm{GH}$ associated with acromegaly and therapeutic application result in increases in circulating concentrations of both IGF-I and IGFBP-3. A protective effect of IGFBP-3 may explain the relatively low incidence of breast and prostate cancers in patients with acromegaly, compared with that which might be predicted from the recent epidemiological studies. The same argument may also imply that chronic GH therapy does not carry such a scale of risk. The recent epidemiological studies, however, raise new questions for which we do not yet have answers. In the light of these new findings more work is obviously indicated to establish the extent of any risk that might be associated with chronic $\mathrm{GH}$ administration. Reassuring evidence comes from very extensive world-wide experience of $\mathrm{GH}$ use in children; this indicates no increase in new cancers or recurrence of past cancers (Blethen et al. 1996). Prostate and breast cancers, however, do not normally present until after puberty and much longer follow-up may be required than hitherto foreseen.

\section{Implications for Cancer Risk Assessment and Risk Reduction: More Intervention to Prevent Cancer?}

If the remarkably strong associations between serum IGF-I levels and risk of breast and prostate cancers are confirmed, then the initial implication would be that measuring such levels may be valuable for identifying subjects with increased risk. A high circulating IGF-I concentration could be used to identify subjects for more regular screening with either PSA measurements or mammograms. Many more men die with prostate cancer than die due to prostate cancer, indicating that many men have prostate cancers which do not present clinically before they die from other causes, and the benefits of screening has not yet been definitively established. Many men with localised cancers may be detected by screening who may not benefit from radical interventions. The strong association between circulating IGF-I and subsequent clinical presentation with prostate cancer suggests that measuring IGF-I as part of a screening profile may provide additional information regarding prognosis, indicating the men more likely to benefit from intervention. Measuring IGF-I may also be of value in monitoring risk reduction strategies. That prophylactic manipulation of hormonal status can actually reduce cancer incidence has very recently been established with the early unblinding of a trial of tamoxifen in women at increased risk of breast cancer in the USA (BCPT, NSABP trial). The reduced incidence in this study was remarkably similar to the reduction in contralateral cancers reported from the 5 year collaborative trial of adjuvant use of tamoxifen in early breast cancer (Early Breast Cancer Collaborative Group 1998). Preliminary data released from two large trials of raloxifene for the treatment of osteoporosis also indicate similar dramatic effects, with breast cancer risk reduced by 58 and $75 \%$ (Lancet, 2 May 1998, p 1335). Other recent prophylactic studies with tamoxifen have, however, failed to find any effect (Pritchard 1998). If the association between IGF-I and risk of breast and prostate cancers is as strong as that of the gonadal steroids, as the recent epidemiological data suggest, then this implies that manipulating IGF-I may also be successful in reducing cancer incidence. Somatostatin is already under investigation for treating a number of cancers (Helle et al. 1998); this or other more specific 
agents for reducing $\mathrm{GH}$ levels might have a place in prophylactic interventions in subjects at high risk. Such pharmacological intervention, as with manipulations of steroid status, will probably be associated with significant adverse side-effects. Circulating IGF-I concentrations are, however, strongly dependent on nutrition, raising the prospect of being able to reduce cancer risk by less aggressive interventions. Investigation of nutritional interventions aimed at reducing serum IGF-I concentrations would be warranted if such reductions were confirmed to reduce the risk of cancer. The evidence indicating programming of cancer risk by early life events suggests that attention to childhood nutrition might provide a good long-term strategy for reducing cancer incidence. However, the epidemiological evidence indicates that some of the anthropometric and nutritional markers associated with increased cancer risk later in life are also associated with decreased risk of insulin resistance and cardiovascular disease later in life. Dietary interventions to reduce risk of cancer may therefore have adverse effects on risks of other disorders; more research is clearly required before public health recommendations can be made. Furthermore, good compliance of populations with effective dietary interventions has in practice proven difficult to achieve.

Together the evidence suggests that the association between IGF-I and cancer incidence complies with many of the accepted criteria for causality (Bradford Hill 1965); the association is strong, specific, demonstrates the correct temporal sequence, is dose responsive, has biological plausibility, and it has coherence with other documented associations. More prospective cohort studies with longer follow-up are required to confirm the association. The last remaining criterion of causality to be satisfied would then depend on interventions, showing that specifically reducing circulating IGF-I levels can reduce cancer incidence.

The main focus of cancer research over the second half of this century has been targeted at unravelling mechanisms whereby genetic damage can initiate cancer; this has been invaluable in advancing knowledge of the cellular mechanisms involved in malignant transformation. The new understanding of cell biology together with the new epidemiology indicates that it may now be productive to place more emphasis on investigating the body's natural defence mechanisms and how these may be influenced in order to avoid cancer. The population studies with oestrogen modifiers indicate that cancer prevention is feasible. Excepting familial cancers, which account for a very small proportion of breast and prostate tumours, and smokingrelated cancers, the new prospective epidemiological studies suggest circulating IGF-I levels to be as strongly associated with risk of these cancer as any other factors yet described. IGF-I would appear to offer attractive avenues for the development of new strategies for cancer prevention.

\section{References}

Albanes D, Jones DY, Schatzkin A, Micozzi MS \& Taylor PR 1988 Adult stature and risk of cancer. Cancer Research 48 1658-1662.

Barres BA, Hart IK, Coles HSR, Burne JF, Voyvodic JT, Richardson WD \& Raff MC 1992 Cell death and control of cell survival in the oligodendrocyte lineage. Cell 70 31-46.

Baserga R, Resnicoff M \& Dews M 1997 The IGF-I receptor and cancer. Endocrine 7 99-102.

Bates P, Fisher R, Ward A, Richardson L, Hill DJ \& Graham CF 1995 Mammary cancer in transgenic mice expressing insulin-like growth factor-II (IGF-II). British Journal of Cancer 72 1189-1193.

Bengtsson B-A, Eden S, Ernest I, Oden A \& Sjogren B 1988 Epidemiology and long-term survival in acromegaly. A study of 166 cases diagnosed between 1955 and 1984. Acta Medica Scandinavica 223 327-335.

Besser M 1997 Growth hormone therapy in adults: a physician's personal view of the need for pharmacovigilance. Endocrinology and Metabolism 4 (Suppl) 87-88.

Blethen SL, Allen DB, Graves D, August G, Moshang T, Rosenfeld R, on behalf of the National Cooperative Growth Study 1996 Safety of recombinant deoxyribonucleic acid derived growth hormone: the National Cooperative Growth Study experience. Journal of Clinical Endocrinology and Metabolism 81 1704-1710.

Bohlke K, Cramer DW, Trichopoulos D \& Mantzoros CS 1998 Insulin-like growth factor-I in relation to premenopausal ductal carcinoma in situ of the breast. Epidemiology 9 570-573.

Bradford Hill A 1965 The environment and disease: association or causation? Proceedings of the Royal Society of Medicine 58 295-300.

Cariani E, Dubois N, Lasserre C, Briand P \& Brechot C 1991 Insulin-like growth factor II (IGF-II) mRNA expression during hepatocarcinogenesis in transgenic mice. Journal of Hepatology $\mathbf{1 3}$ 220-226.

Carroll PV, Christ ER, Bengtsson BA, Carlsson L, Christiansen JS, Clemmons D, Hintz R, Ho K, Laron Z, Sizonenko P, Sonksen PH, Tanaka T \& Thorner M 1998 Growth hormone deficiency in adulthood and the effects of growth hormone replacement: a review. Journal of Clinical Endocrinology and Metabolism 83 382-395.

Cats A, Dullaart RP, Kliebeuker JH, Kuipers F, Sluiter WJ, Hardonk MJ \& de Vries EG 1996 Increased epithelial cell proliferation in the colon of patients with acromegaly. Cancer Research 56 523-526.

Chan JM, Stampfer MJ, Giovannucci E, Gann PH, Ma J, Wilkinson P, Hennekens CH \& Pollak M 1998 Plasma insulin-like growth factor-I and prostate cancer risk: a prospective study. Science $\mathbf{2 7 9}$ 563-566.

Christofori G, Naik P \& Hanahan D 1994 A second signal supplied by insulin-like growth factor II in oncogene-induced tumorigenesis. Nature 369 414-418.

Chute CG, Willett WC, Colditz GA, Stampfer MJ, Baron JA, Rosner B \& Speizer FE 1991 A prospective study of body mass, height and smoking on the risk of colorectal cancer in women. Cancer Causes and Control 2 117-124.

Cianfarani S, Tedeschi B, Germani D, Prete SP, Rossi P, Vernole P, Caporossi D \& Boscerini B 1998 In vitro effects of growth hormone (GH) and insulin-like growth factor I and II (IGF-I and -II) on chromosome fragility and $\mathrm{p} 53$ protein expression in human lymphocytes. European Journal of Clinical Investigation 28 41-47.

Clark PA \& Rogol AD 1996 Growth hormones and sex steroid interactions at puberty. Endocrinology and Metabolism Clinics of North America. 25 665-681.

Cohen SM \& Ellwein LB 1990 Cell proliferation in carcinogenesis. Science 249 1007-1011.

Colao AM, Marzullo O, Ferone D, Spiezia S, Cerbone G, Marino V, Di Sarno A, Merola B \& Lombardi G 1998 Prostatic hyperplasia: an unknown feature of acromegaly. Journal of Clinical Endocrinology and Metabolism 83 775-779.

Corpas E, Harman SM \& Blackman MR 1993 Human growth hormone and human aging. Endocrine Reviews 14 20-39. 
Culig Z, Hobisch A, Cronauer MV, Radmayr C, Trapman J, Hittmair A, Bartsch G \& Klocker H 1994 Androgen receptor activation in prostate tumor cell lines by insulin-like growth factor-I, keratinocyte growth factor, and epidermal growth factor. Cancer Research 54 5474-5478.

Cuneo RC, Judd S, Wallace JD, Perry-Keene D, Burger H, Lim-Tio S, Strauss B, Stockigt J, Topliss D, Alford F, Hew L, Bode H, Conway A, Handelsman D, Dunn S, Boyages S, Wah Cheung N \& Hurley D 1998 The Australian multicenter trial of growth hormone $(\mathrm{GH})$ treatment in GH-deficient adults. Journal of Clinical Endocrinology and Metabolism 83 107-116.

Damon SE, Maddison L, Ware JL \& Plymate SR 1998 Overexpression of an inhibitory insulin-like growth factor binding protein (IGFBP), IGFBP-4, delays onset of prostate tumor formation. Endocrinology 139 3456-3464.

Davenport ML, Clemmons DR, Miles MV, Camacho-Hubner C, D'Ercole AJ \& Underwood LE 1990 Regulation of serum insulin-like growth factor-I (IGF-I) and IGF binding proteins during rat pregnancy. Endocrinology 127 1278-1286.

De Mellow JSM, Handelsman DJ \& Baxter RC 1987 Short-term exposure to insulin-like growth factors stimulates testosterone production by testicular interstitial cells. Acta Endocrinologica 115 483-489.

Dorgan JF, Longcope C, Stephenson HE, Falk RT, Miller R, Franz C, Kahle L, Campbell WS, Tangrea JA \& Schatzkin A 1997 Serum sex hormone levels are related to breast cancer risk in postmenopausal women. Environmental Health Perspectives 105 (Suppl 3) 583-585.

Early Breast Cancer Trialist Collaborative Group 1998 Tamoxifen for early breast cancer: an overview of the randomised trials. Lancet 351 1451-1467.

Eriksson L, Frankenne F, Eden S, Hennen G \& Von Schoultz B 1989 Growth hormone 24-h serum profiles during pregnancy - lack of pulsatility for the secretion of the placental variant. British Journal of Obstetrics and Gynaecology 96 949-953.

Fazio S, Sabatini D, Capaldo B, Vigorito C, Giordano A, Guida R, Pardo F, Biondi B \& Sacca L 1996 A preliminary study of growth hormone in the treatment of dilated cardiomyopathy. New England Journal of Medicine 334 809-814.

Fisher DE 1994 Apoptosis in cancer therapy: crossing the threshold. Cell 78 539-542.

Frankel S, Gunnell DJ, Peters TJ, Maynard M \& Davey Smith G 1998 Childhood energy intake and adult mortality from cancer: the Boyd Orr cohort study. British Medical Journal 316 499-504.

Gann PH, Hennekens CH \& Stampfer MJ 1995 A prospective evaluation of plasma prostate specific antigen for detection of prostate cancer. Journal of the American Medical Association 273 289-294.

Gann PH, Hennekens CH, Ma J, Longcope C \& Stampfer MJ 1996 Prospective study of sex hormone levels and risk of prostate cancer. Journal of the National Cancer Institute 88 1118-1126.

Gill ZP, Perks CM, Newcomb PVN \& Holly JMP 1997 Insulin-like growth factor binding protein-3 (IGFBP-3) predisposes breast cancer cells to programmed cell death in a non-IGF dependent manner. Journal of Biological Chemistry 272 25602-25607.

Giovannucci E, Rim EB, Stampfer MJ, Colditz GA \& Willett WC 1997 Height, body weight, and risk of prostate cancer. Cancer Epidemiology, Biomarkers and Prevention 6 557-563.

Giovannucci E, Rim EB, Stampfer MJ, Colditz GA \& Willett WC 1998 Diabetes mellitus and risk of prostate cancer (United States). Cancer Causes and Control 9 3-9.

Giudice LA 1992 Insulin-like growth factors and ovarian follicular development. Endocrine Reviews 13 641-669.

Goodman-Gruen D \& Barrett-Connor E 1997 Epidemiology of insulin-like growth factor-I in elderly men and women. The Rancho Bernardo Study. American Journal of Epidemiology 1997145 970-976.
Gunnell DJ, Davey Smith G, Frankel S, Nanchahal K, Braddon FEM, Pemberton J \& Peters TJ 1998a Childhood leg length and adult mortality: follow up of the Carnegie (Boyd Orr) Survey of Diet and Health in Pre-war Britain. Journal of Epidemiology and Community Health $\mathbf{5 2}$ 142-152.

Gunnell DJ, Davey Smith G, Holly JMP \& Frankel S 1998b Leg length and cancer risk: indirect evidence of an aetiological role for growth factors in the Boyd Orr cohort. British Medical Journal (In Press).

Hankinson SE, Willett WC, Manson JE, Hunter DJ, Colditz GA, Stampfer MJ, Longcope C \& Speizer FE 1995 Alcohol, height, and adiposity in relation to estrogen and prolactin levels in postmenopausal women. Journal of the National Cancer Institute $\mathbf{8 7}$ $1297-1302$.

Hankinson SE, Willett WC, Colditz GA, Hunter DJ, Michaud DS, Deroo B, Rosner B, Speizer FE \& Pollak M 1998 Circulating concentrations of insulin-like growth factor-I and risk of breast cancer. Lancet 351 1393-1396.

Harrington EA, Bennett MR, Fanidi A \& Evan GI 1994 c-Myc-induced apoptosis in fibroblasts is inhibited by specific cytokines. EMBO Journal 199413 3286-3295.

Harris JR, Lippman ME, Morrow M \& Hellman S Eds 1996 Diseases of the Breast. Philadelphia: Lippincott-Raven Publishers.

Haymond MW \& Mauras N 1996 The rationale for the use of recombinant human growth hormone and insulin-like growth factor-I for catabolic conditions in humans. Hormone Research 46 202-207.

Helle SI, Holly JMP, Tally M, Hall K, van der Stappen J \& Lonning PE 1996 Influence of treatment with tamoxifen and change in tumor burden on the IGF-system in breast cancer patients. International Journal of Cancer 69 335-339.

Helle SI, Geisler J, Poulsen JP, Hestdal K, Meadows K, Collins W, Tveit KM, Viste A, Holly JMP \& Lonning PE 1998 Microencapsulated octreotide pamoate in advanced gastrointestinal and pancreatic cancer: a phase I study. British Journal of Cancer $\mathbf{7 8}$ $14-20$.

Hunter DJ \& Willett WC 1993 Diet, body size and breast cancer. Epidemiologic Reviews 15 110-132.

Invited Report of a Workshop 1998 Consensus guidelines for the diagnosis and treatment of adults with growth hormone deficiency: summary statement of the Growth Hormone Research Society workshop on adult growth hormone deficiency. Journal of Clinical Endocrinology and Metabolism 83 379-381.

Jörgensen JOL, Moller N, Lauritzen T \& Christiansen JS 1990 Pulsatile versus continuous intravenous administration of growth hormone $(\mathrm{GH})$ in $\mathrm{GH}$-deficient patients: effects on circulating insulin-like growth factor-I and metabolic indices. Journal of Clinical Endocrinology and Metabolism 70 1616-1623.

Lambe M, Hsieh C, Trichopoulos D, Ekbom A, Pavia M \& Adami HO 1994 Transient increase in the risk of breast cancer after giving birth. New England Journal of Medicine 331 5-9.

Lancet 1998 News: Second drug said to reduce breast cancer risk. Lancet 3511335.

Lee AV, Weng CN, Jackson JG \& Yee D 1997 Activation of estrogen receptor mediated gene transcription by IGF-I in human breast cancer cells. Journal of Endocrinology 152 39-47.

Leon DA, Davey Smith G, Shipley M \& Strachan D 1995 Adult height and mortality in London: early life, socioeconomic confounding, or shrinkage? Journal of Epidemiology and Community Health 49 5-9.

Loeb LA 1991 Mutator phenotype may be required for multistage carcinogenesis. Cancer Research 51 3075-3079.

Lucidi P, Lauteri M, Laureti S, Celleno R, Santoni S, Volpi E, Angeletti G, Santeusanio F \& De Feo P 1998 A dose-response study of growth hormone $(\mathrm{GH})$ replacement on whole body protein and lipid kinetics in GH-deficient adults. Journal of Clinical Endocrinology and Metabolism 83 353-357. 
Maison P, Balkau B, Simon D, Chanson P, Rosselin G \& Eschwege E 1998 Growth hormone as a risk for premature mortality in healthy subjects: data from the Paris prospective study. British Medical Journal 316 1132-1133.

Marcelli M, Haidacher SJ, Plymate SR \& Birnbaum RS 1995 Altered growth and insulin-like growth factor-binding protein-3 production in PC-3 prostate carcinoma cells stably transfected with a constitutively active androgen receptor complementary deoxyribonucleic acid. Endocrinology 136 1040-1048.

Michels KB, Trichopoulos D, Robins JM, Robins JM, Rosner BA, Manson JE, Hunter DJ, Colditz GA, Hankinson SE, Speizer FE \& Willett WC 1996 Birthweight as a risk factor for breast cancer. Lancet 348 1542-1546.

Nabarro JDN 1987 Acromegaly. Clinical Endocrinology 26 481-512.

Ng ST, Zhou J, Adesanya OO, Wang J, LeRoith D \& Bondy CA 1997 Growth hormone treatment induces mammary gland hyperplasia in aging primates. Nature Medicine 3 1141-1144.

Orme SM, McNally R, Staines A, Cartwright RA \& Belchetz PE 1996 Cancer incidence and mortality in acromegaly: a retrospective cohort study. Journal of Endocrinology 148 (Suppl) OC22.

Orme SM, McNally RJQ, Cartwright RA \& Belchetz PE 1998 Mortality and cancer incidence in acromegaly: a retrospective cohort study. Journal of Clinical Endocrinology and Metabolism 83 2730-2734.

Orr-Weaver TL \& Weinberg RA 1998 A checkpoint on the road to cancer. Nature 392 223-224.

Pritchard KI 1998 Is tamoxifen effective in prevention of breast cancer? Lancet 352 80-81.

Rajah R, Valentinis B \& Cohen P 1997 Insulin-like growth factor (IGF)-binding protein-3 induces apoptosis and mediates the effects of transforming growth factor- $\beta 1$ on programmed cell death through a p53- and IGF-independent mechanism. Journal of Biological Chemistry 272 12181-12188.

Resnicoff M \& Baserga R 1998 The role of the insulin-like growth factor I receptor in transformation and apoptosis. Annals of the New York Academy of Sciences 842 76-81.

Rogler CE, Yang D, Rossetti L, Donohoe J, Alt E, Chang CJ, Rosenfeld R, Neely K \& Hintz R 1994 Altered body composition and increased frequency of diverse malignancies in insulin-like growth factor-II transgenic mice. Journal of Biological Chemistry 269 13779-13784.

Schirmacher P, Held WA, Yang D, Chisari FV, Rustum Y \& Rogler CE 1993 Reactivation of insulin-like growth factor II during hepatocarcinogenesis in transgenic mice suggests a role in malignant growth. Cancer Research 52 2549-2556.

Smith-Warner SA, Spiegelman D, Shiaw-Shyuan Y, Van den Brandt PA, Folsom AR, Goldbohm A, Graham S, Holmberg L, Howe GR, Marshall JR, Miller AB, Potter JD, Speizer FE, Willett WC, Wolk A \& Hunter DJ 1998 Alcohol and breast cancer in women. A pooled analysis of cohort studies. Journal of the American Medical Association 279 535-540.

Taback SP, Collu R, Deal CL, Guyda HJ, Salisbury S, Dean HJ \& Van Vliet G 1996 Does growth hormone supplementation affect adult height in Turner's syndrome? Lancet 348 25-27.

Tedeschi B, Spadoni GL, Sanna ML, Vernole P, Caporossi D, Cianfarani S, Nicoletti B \& Boscherini B 1993 Increased chromosome fragility in lymphocytes of short normal children treated with recombinant human growth hormone. Human Genetics 91 459-463.

Thissen J-P, Ketelslegers J-M \& Underwood LE 1994 Nutritional regulation of the insulin-like growth factors. Endocrine Reviews $\mathbf{1 5}$ 80-101.

Tibblin G, Eriksson M, Cnattingius S \& Ekbom A 1995 High birthweight as a predictor of prostate cancer risk. Epidemiology 6 423-424.

Tornell J, Carlsson B, Pohjanen P, Wennbo H, Rymo L \& Isaksson OGP 1992 High frequency of mammary adenocarcinomas in metallothionein promoter-human growth hormone transgenic mice created from two different strains of mice. Journal of Steroid Biochemistry and Molecular Biology 43 237-242.

Westley BR \& May FEB 1994 Role of insulin-like growth factors in steroid modulated proliferation. Journal of Steroid Biochemistry and Molecular Biology 51 1-9.

Wolk A, Mantzoros CS, Andersson S-O, Bergstrom R, Signorello LB, Lagiou P, Adami H-O \& Trichopoulos D 1998 Insulin-like growth factor I and prostate cancer risk: a population-based, case-control study. Journal of the National Cancer Institute 90 911-915.

Zumoff B 1997 The critical role of alcohol consumption in determining the risk of breast cancer with postmenopausal estrogen administration. Journal of Clinical Endocrinology and Metabolism 82 $1656-1658$.

\section{Received 18 August 1998}

Accepted 3 November 1998 